\title{
POKDARWIS (Kelompok Sadar Wisata) Desa Koto Sentajo Mempromosikan Objek Wisata Budaya Rumah Godang
}

\author{
Genny Gustina Sari ${ }^{1}$, Yohannes Firzal ${ }^{2}$ \\ 1, 2 Fakultas IImu Sosial dan IImu Politik, Universitas Riau, Riau, Indonesia
}

\begin{abstract}
ABSTRAK
Salah satu desa di Kecamatan Kuantan Singingi Provinsi Riau yakni Desa Koto Sentajo ternyata menyimpan pesona wisata budaya berupa Rumah Godang yang merupakan warisan sejarah dan budaya masyarakat melayu di sana. Yang menarik dari rumah godang ini adalah karena mereka berada dalam satu lingkup wilayah sehingga sangat cocok dijadikan pilihan wisata budaya yang komplit dan unik. Sebagai upaya meningkatkan minat pengunjung, Tim Pengabdian Kepada Masyarakat Universitas Riau bekerjasama dengan Pemerintah Daerah berencana membantu masyarakat untuk lebih mengetahui dan mahir melakukan strategi dan teknik komunikasi persuasif melalui POKDARWIS (Kelompok Sadar Wisata). Pengabdian ini direncanakan akan dilaksanakan selama 3 tahun berturutturut. Pada tahun pertama 2018, kami berhasil memetakan kembali jenis rumah Godang yang ada di Desa Koto Sentajo, tim pengabdian mendampingi masyarakat membuat papan nama masing-masing rumah Godang, membuat kalender promosi, serta membuat peta desa. Tim pengabdian membantu promosi melalui pemberitaan dibeberapa media lokal, mempresentasikan hasil temuan di seminar nasional, menganalisis potensi desa serta hambatan yang dialami. Pengabdian tahun kedua lebih di fokuskan pada strategi komunikasi masyarakat dalam mempromosikan objek wisata. Dari segi komunikator, Tim Pengabdian dan pemerintah telah mengadakan pelatihan Tour Guide bagi remaja di Desa Sentajo. Dari segi Pesan saat ini telah diadakan pelatihan pembuatan web yang akan didampingi sampai web tersebut bisa di operasikan oleh POKDARWIS, khalayak tujuan juga saat ini dikembangkan dengan tidak lagi fokus hanya pada masyarakat di sekitar desa atau Provinsi Riau, tetapi juga meluas ke Provinsi lain seperti Sumatera Barat, Medan dan Aceh. Tidak lupa, tim bersama POKDARWIS juga mengadakan pelatihan pemanfaatan new media agar masyarakat bisa membantu pemerintah dalam mempromosikan wisata budaya Rumah Godang.
\end{abstract}

Kata kunci: Koto Sentajo, Desa Cagar Budaya, Rumah Godang

\begin{abstract}
One of the villages in Kuantan Singingi Subdistrict, Riau Province, namely Koto Sentajo Village turned out to save the charm of cultural tourism in the form of Rumah Godang which is a historical and cultural heritage of Malay people there. The interesting thing about this godang house is because they are in one area so it is very suitable to be chosen as a complete and unique cultural tourism choice. In an effort to increase visitor interest, the University of Riau Community Service Team in collaboration with the Regional Government plans to help the community to be more aware and adept at performing persuasive communication strategies and techniques through POKDARWIS (Tourism Awareness Group). This service is planned to be held for 3 consecutive years. In the first year of 2018, we succeeded in remapping the type of Godang house in Koto Sentajo Village, the community service team assisted the community to make a signboard for each Godang house, create a promotional calendar, and map the village. The dedication team helped with promotion through reporting in several local media,
\end{abstract}


presenting findings at national seminars, analyzing village potential and obstacles encountered. Second year service is more focused on community communication strategies in promoting tourism objects. In terms of communicators, the Community Service Team and the government held a Tour Guide training for teenagers in Sentajo Village. In terms of the message, there has been a web-making training that will be accompanied until the web can be operated by POKDARWIS, the target audience is also currently being developed by no longer focusing solely on communities around the village or Riau Province, but also extending to other provinces such as Sumatra West, Medan and Aceh. Not to forget, the team together with POKDARWIS also held training on utilizing new media so that the community could help the government in promoting the cultural tourism of Rumah Godang.

Keywords: Koto Sentajo, cultural heritage village, Rumah Godang

\section{PENDAHULUAN}

Provinsi Riau sebagai peraih juara umum tempat pariwisata terpopuler di ajang Anugerah Pesona Indonesia 2017 yang diselenggarakan Kementerian Pariwisata, prestasi ini menjadi pendorong dan motivasi untuk memajukan pariwisata dan ekonomi kreatif di Riau. Sebagai pemenang akan mendapat tuntutan dalam mempertahankan prestasi tersebut, untuk itu perlu kerjasama yang erat antara pemerintah dan masyarakat. Potensi wisata ini sangat memberikan manfaat yang tinggi bagi pendapatan daerah. Salah satu potensi wisata cagar budaya yang terdapat di Riau terletak di Koto Sentajo, Kecamatan Sentajo Raya, kabupaten Kuantan Singingi. Kebudayaan Kuantan Singingi memiliki nilai jual yang sangat eksotis tahun 2017 Kebudayaan Kuantan Singingi termasuk dalam Kawasan Strategis Pariwisata Nasional (KSPN) dan termasuk tujuan wisata budaya utama di Riau.

Kenegerian Sentajo terletak sekitar tujuh kilometer dari Ibukota Kabupaten Kuantan Singingi, Teluk Kuantan. Di kawasan ini, terdapat delapan belas rumah adat yang disebut rumah godang. Ada empat subetnis terbesar yang merupakan suku terbesar di daerah Kuantan Singingi yaitu, Suku Piliang, Suku Caniago, Suku Patopang, dan Suku Melayu. Keberadaan kawasan rumah godang ini sudah ada sejak 2,5 abad silam. Seterusnya rumah godang juga digunakan sebagai tempat memberi penghormatan dengan doa, saat pembesar adat masingmasing sub-etnis meninggal dunia, seperti penghulu, menti, dan dubalang.

Pada awalnya Kenegerian Sentajo yang terdiri dari 5 (lima) Desa yaitu Pulau Komang, Muaro, Koto, Kampung Baru dan Pulau Kopang Sentajo, namun setelah terjadi pemekaran menjadi kecamatan Sentajo Raya, kenegerian sentajo menjadi 15 Desa. Adat Istiadat di kenegerian Sentajo sampai saat ini masih tetap terjaga walaupun harus menyesuaikan dengan kamajuan zaman. Salah satu cara dalam melestarikan kebudayaan adalah dengan fungsi rumah Godang Sentajo sebagai pusat dari kebudayaan itu sendiri, kegiatan-kegiatan adat yang dilaksanakan di Rumah Godang menandakan bahwa rumah merupakan pusat dari aktivitas adat.

Untuk mewujudkan desa wisata unggulan Sentajo Raya, penulis menemukan beberapa kendala dan permasalahan pada saat melakukan observasi awal, yaitu: tidak terdapat 
petunjuk jalan yang mengarahkan wisatawan menuju kawasan desa wisata Koto Sentajo; gapura kawasan kenegerian desa cagar budaya wisata yang dinilai tidak menarik; alur arah peta bagi wisatawan di dalam kawasan desa Sentajo Raya yang nantinya akan mengarahkan wisatawan selama di sana; papan informasi masing-masing situs wisata baik untuk rumah godang maupun masjid Jami'; ketersediaan SDM sebagai tour guide dan pengelola yang memberikan informasi bagi wisatawan yang berkunjung; fasilitas umum seperti kamar mandi dan bangku taman untuk wisatawan; dan peranan POKDARWIS (Kelompok Sadar Wisata) di Desa Koto Sentajo.

POKDARWIS ini merupakan kelompok swadaya dan swakarsa masyarakat yang dalam aktivitas sosialnya berupaya untuk meningkatkan pemahaman kepariwisataan serta partisipasi masyarakat dalam pembangunan kepariwisataan daerahnya masing-masing. Keberadaan POKDARWIS di suatu daerah sangat berpengaruh terhadap peningkatan wisata di daerah tersebut. Namun perlu digaris bawahi peranan POKDARWIS bisa efektif jika masingmasing divisi terjalin komunikasi yang efektif.

Penelitian Suryawan (2016) dengan judul Peran Kelompok Sadar Wisata (POKDARWIS) Sendang Arum dalam pengembangan potensi pariwisata (Studi Kasus di desa wisata Tlahap Kecamatan Kledung Kabupaten Temanggung) pada tahun 2016. Hasil penelitian menunjukan bahwa: (1) Peran Pokdarwis Sendang Arum; (a) Memperkenalkan, melestarikan, dan memanfaatkan pontensi wisata; (b) Mengelola pariwisata; (c) Meningkatkan pengetahuan dan keterampilan anggota serta masyarakat; (d) Menjalin kerjasama dengan organisasi lain. (2) Faktor pendukung Pokdarwis Sendang Arum, yaitu: dukungan Pemerintah Kabupaten Temanggung, sumber daya alam yang melimpah, sumber daya manusia, peninggalan kebudayaan Mataram Kuno dan kearifan lokal yang tetap dilestarikan. Sedangkan Faktor penghambatnya, yaitu: Kurangnya partisipasi masyarakat dan kurangnya kesadaran serta aktualisasi masyarakat terhadap sapta pesona. (4) Dampak peran Pokdarwis Sendang Arum, yaitu: Salah satu Desa Wisata terbaik, pendapatan Desa Wisata Tlahap dan jumlah kunjungan wisatawan meningkat, serta dapat membuka lapangan pekerjaan.

Apa yang penulis temukan di lapangan menunjukkan kurang aktifnya POKDARWIS di Desa Koto Sentajo Kabupaten Kantan Singingi. Tidak jelas permasalahan internal dalam kelompok, namun penulis menemukan rendahnya minat anggota kelompok untuk berkumpul serta kurangnya kreatifitas dan antusias anggota kelompok dalam upaya memajukan wisata Rumah Godang disana. Penelitian ini bertujuan untuk mengetahui bagaimana strategi komunikasi POKDARWIS Desa Koto Sentajo dalam mempromosikan objek wisata rumah godang. Penelitian ini diharapkan mampu memberikan kontribusi bagi peningkatan peran dan fungsi POKDARWIS tersebut kedepannya dengan menganalisis kelebihan dan kekurangan kelompok tersebut. 


\section{METODOLOGI PELAKSANAAN}

POKDARWIS adalah kelembagaan di tingkat masyarakat yang anggotanya terdiri dari para pelaku kepariwisataan yang memiliki kepedulian dan tanggungjawab serta berperan sebagai penggerak dalam mendukung terciptanya iklim kondusif bagi tumbuh dan berkembangnya kepariwisataan serta terwujudnya Sapta Pesona dalam meningkatkan pembangunan daerah melalui kepariwisataan dan manfaatkannya bagi kesejahteraan masyarakat sekitar. Mengembangkan kelompok masyarakat yang dapat berperan sebagai motivator, penggerak serta komunikator dalam upaya meningkatkan kesiapan dan kepedulian masyarakat di sekitar destinasi pariwisata atau lokasi daya tarik wisata agar dapat berperan sebagai tuan rumah yangbaik bagi berkembangnya kepariwisataan, serta memiliki kesadaran akan peluang dan nilai manfaat yang dapat dikembangkan dari kegiatan pariwisata untuk meningkatkan kesejahteraan ekonomi masyarakat.

Tujuan dari pembentukan Kelompok Sadar Wisata (Pokdarwis) ini adalah sebagai berikut: (1) meningkatkan posisi dan peran masyarakat sebagai subjek atau pelaku penting dalam pembangunan kepariwisataan, serta dapat bersinergi dan bermitra dengan pemangku kepentingan terkait dalam meningkatkan kualitas perkembangan kepariwisataan di daerah; (2) membangun dan menumbuhkan sikap dan dukungan positif masyarakat sebagai tuan rumah melalui perwujudan nilai-nilai Sapta Pesona bagi tumbuh dan berkembangnya kepariwisataan di daerah dan manfaatnya bagi pembangunan daerah maupun kesejahteraan masyarakat; (3) memperkenalkan, melestarikan dan memanfaatkan potensi daya tarik wisata yang ada di masing-masing daerah.

Secara umum, fungsi POKDARWIS dalam kegiatan kepariwisataan adalah: sebagai penggerak Sadar Wisata dan Sapta Pesona di lingkungan wilayah di destinasi wisata dan sebagai Mitra Pemerintah dan pemerintah daerah (kabupaten/kota) dalam upaya perwujudan dan pengembangan Sadar Wisata di daerah (Rahim, 2012: 16-18).

Wisata budaya merupakan kegiatan wisata yang bertujuan rekreasi serta mempelajari daya tarik budaya dengan memanfaatkan potensi budaya dari tempat yang dikunjungi. Salah satu penyebab seseorang ingin melakukan perjalanan wisata adalah adanya keinginan mempelajari budaya di suatu daerah (Pitama \& Diarta, 2009 :75). Atraksi wisata budaya yang terdapat di Desa Koto Sentajo diantaranya adalah rumah godang, rumah jalur, randai, magrib mengaji, silat dan tradisi memulai musim tanam. Berikut akan dijelaskan mengenai potensi atraksi budaya di Desa Koto Sentajo. Wisata alam yang terdapat di Desa Koto Sentajo diantaranya adalah sungai Rutopang dan Batang Koban, areal persawahan, perkebunan, peternakan dan hutan lindung Sentajo. 


\section{HASIL DAN DISKUSI}

Keberadaan POKDARWIS di Desa Koto Sentajo telah dibentuk sejak tahun 2016 namun sampai saat ini aktivitas POKDARWIS di desa tersebut masih minim. Hasil observasi dilapangan menunjukkan kurangnya minat masyarakat di Desa Koto Sentajo untuk mengaktifkan dan mempromosikan objek wisata budaya mereka. Desa Koto Sentajo telah ditetapkan menjadi desa wisata oleh pemerintah Kabupaten Kuantan Singigi. Namun desa ini belum memiliki pemandu wisata bagi pengunjung yang datang. Pemandu wisata ini cukup penting untuk mengantar dan memberikan informasi kepada wisatawan. Wisatawan yang baru pertama kali datang biasanya memiliki rasa ingin tahu mengenai budaya di Desa Koto Sentajo. Dengan adanya pemandu wisata pengunjung akan memiliki tempat untuk bertanya. Pengunjung akan merasa lebih dekat dengan masyarakat lokal terutama jika pengunjung tersebut menginap di desa.

Desa wisata berupa wilayah pedesaaan yang menawarkan keseluruhan suasana yang mencerminkan dan menonjolkan keaslian desa.Bentuknya dapat berupa arsitektur bangunan dan struktur tata ruang desa, adat istiadat keseharian, kehidupan sosial budaya, serta potensi kepariwisataan yang lain, semisal atraksi budaya, atraksi alam, kuliner, kerajinan tangan dan cenderamata, penginapan, serta kebutuhan wisata lainnya. Tim pengabdian melihat adanya sikap apatis masyarakat dan nilai-nilai yang mereka anut menimbulkan kesulitan untuk mempromosikan objek wisata budaya Rumah Godang. Beberapa alasan dan kendala yang tim temukan dilapangan antara lain: munculnya anggapan bahwa wisatawan yang datang akan merusak kemurnian adat dan nilai-nilai yang dianut masyarakat Desa Koto Sentajo; keterbatasan kemampuan masyarakat dalam mengoperasikan teknologi informasi menyebabkan masyarakat pesimis bisa menarik minat wisatawan; generasi muda Desa Koto Sentajo mayoritas memilih merantau ke kota daripada tinggal dan mengembangkan daerahnya; masyarakat tidak menganggap Rumah Godang yang mereka diami memiliki nilai tinggi untuk menarik wisatawan datang sehingga upaya untuk merawat dan melestarikan Rumah Godang yang sangat minim; keterbatasan sarana dan prasarana seperti tempat MCK, homestay bagi wisatawan, klinik kesehatan, restoran yang menyediakan makanan khas Koto Sentajo, Galeri oleh-oleh dan transportasi disekitar Desa Koto Sentajo; dan kurangnya minat masyarakat Desa Koto Sentajo untuk menghidupkan kegiatan-kegiatan di POKDARWIS menyebabkan para pengurusnya lebih memilih untuk pasif.

Terkait permasalahan di atas, tim pengabdian melakukan beberapa kegiatan yang bertujuan untuk memancing kembali semangat masyarakat Desa Koto Sentajo khususnya POKDARWIS di desa tersebut.

Pelaksanaan pelatihan komunikasi efektif dan public speaking yang dilakukan untuk semua lapisan masyarakat di Desa Koto Sentajo. Hal ini bertujuan agar semua masyarakat mampu dan bisa memahami hakikat komunikasi efektif. Tujuan pelatihan ini untuk meningkatkan 
pemahaman dan kesadaran masyarakat bahwa rasa nyaman dan keramahtamahan merpakan point utama yang harus dimiliki oleh pemandu wisata. Pelatihan ini dihadiri oleh 50 orang peserta termasuk sebagain besar anggota POKDARWIS dan diharapkan kedepannya, masyarakat Desa Koto Sentajo khususnya POKDARWIS mampu membangun komunikasi efekatif dan kooperatif dalam memberikan informasi wisata buda Desa Rumah Godang di Desa Sentajo, Kabupaten Singingi.

Pelaksanaan pelatihan web bagi generasi muda Desa Koto Sentajo. Tim pengabdian menyadari bahwa penyebaran informasi sudah tidak lagi dari mulut ke mulut, namun di era New Media saat ini, mau tidak mau masyarakat akan bersentuhan dengan yang namanya teknologi. Hasil observasi dilapangan menunjukkan bahwa sebagian besar masyarakat di Desa Koto Sentajo khususnya para generasi muda sudah menggunakan teknologi seperti HP Android, sudah memiliki akun social media bahkan beberapa cukup aktif mengunggah kegiatan mereka di akun sosialnya. Hal ini yang kemudian menjadi dasar bagi tim pengabdian untuk mengadakan pelatihan pembuatan dan pengoperasian web bagi masyarakat Desa Koto Sentajo. Pelatihan ini memakan waktu yang cukup lama. Sampai kegiatan ini selesai dilaksanakan, tim bersama masyarakat belum berhasil membuat web desa dikarenakan kendala teknis dan waktu pelatihan yang mundur dari jadwal yang telah ditetapkan.

Mendata dan mengumpulkan ibu-ibu untuk merumuskan dan mengklasifikasikan masakan khas Desa Koto Sentajo. Salah satu tujuan wisata bagi wisatawan selain melihat keindahan alam, keunikan suatu daerah adalah mencicipi makanan khas daerah tersebut. Tim pengabdian bersama POKDARWIS Desa Koto Sentajo melakukan beberapa kegiatan: (a) Mendata jenis-jenis makanan khas Desa Koto Sentajo khususnya yang sudah lama tidak lagi dimasak masyarakat. Tim pengabdian bersama anggota POKDARWIS menemui para orang tua desa yang masih mengetahui resep-reser kuliner lama yang tidak dibuat lagi. (b) Mengumpulkan ibu-ibu masyarakat Desa Koto Sentajo melalui POKDARWIS membagi mereka menjadi 4 kelompok untuk mempelajari resep makanan yang telah tim bagi menjadi 4 kategori yaitu, lauk, minuman, camilan dan makanan hasil kreasi. Tim pengabdian membagi ibu-ibu dan remaja putri kedalam empat kelompok yang kemudian akan dilatih dan dibimbing oleh orang tua desa menyiapkan kuliner yang nantinya akan diperkenalkan pada wisatawan. (c) Mengadakan pestival kuliner desa yang disesuaikan dengan event Pacu Jalur pada tahun 2020. (d) Membuat buku saku kuliner Desa Koto Sentajo. Dalam hal ini tim membuat buku saku kuliner dengan memfoto makanan tersebut, menjelaskan tahap-tahap pengolahan, bahan-bahan yang dibutuhkan hingga sejarah dan kapan waktu dibuat makanan tersebut.

Melaksanakan pendampingan pembuatan flyer dan Peta Desa. Salah satu media promosi yang bertujuan tidak hanya mempromosikan wisata budaya di Desa Koto Sentajo, namun juga sebagai media informasi bagi calon wisatawan adalah dengan membuat flyer dan peta desa. Saat ini flyer masih dalam tahap penyelesaian dan peta desa sudah selesai dibuat dan dipajang di depan gerbang masuk Desa Koto Sentajo. 
Gambar 1. Peta Desa Koto Sentajo

\section{PETA KOTO SENTAJO}

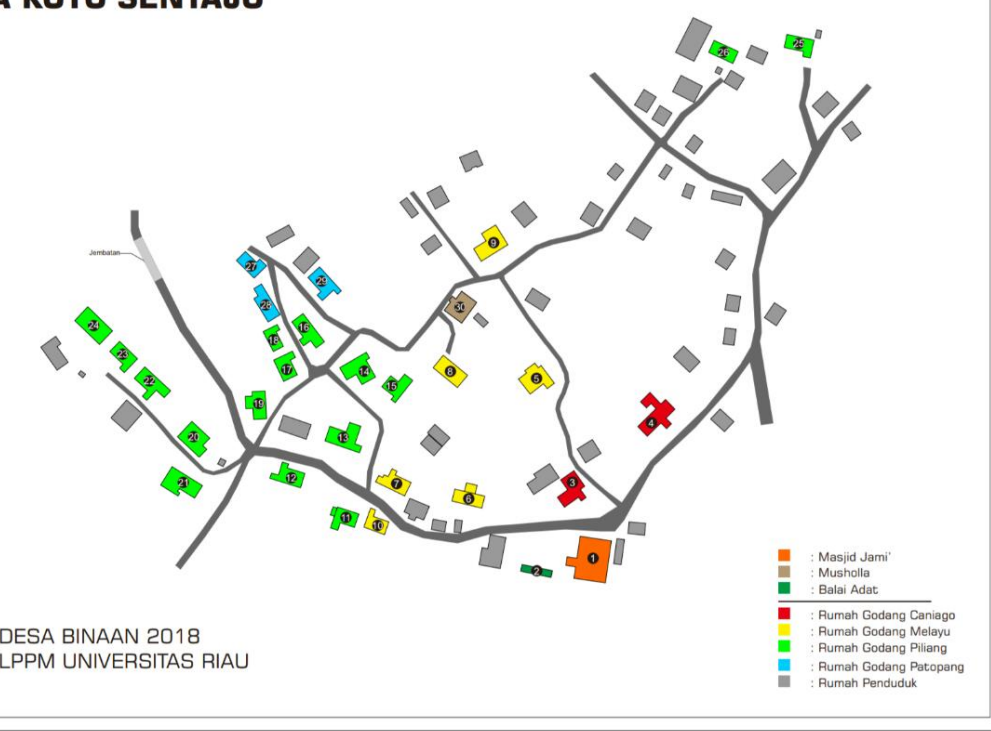

Tabel 7. Media Promosi Komunikasi Desa Wisata Desa Koto Sentajo

\begin{tabular}{|c|c|}
\hline Publikasi & Media \\
\hline $\begin{array}{l}\text { http://www.riauonline.co.id/riau/ } \\
\text { kota- } \\
\text { pekanbaru/read/2018/09/18/unri } \\
\text {-persiapkan-koto-sentajo- } \\
\text { sebagai-destinasi-wisata-budaya }\end{array}$ & 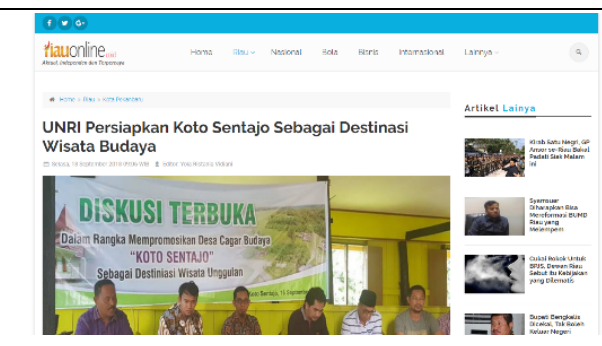 \\
\hline $\begin{array}{l}\text { http://m.liputanoke.com/read- } \\
\text { 27830-2018-09-18-unri- } \\
\text { persiapkan-rumah-adat- } \\
\text { kenegerian-sentajo-sebagai- } \\
\text { destinasi-wisata-budaya.html }\end{array}$ & 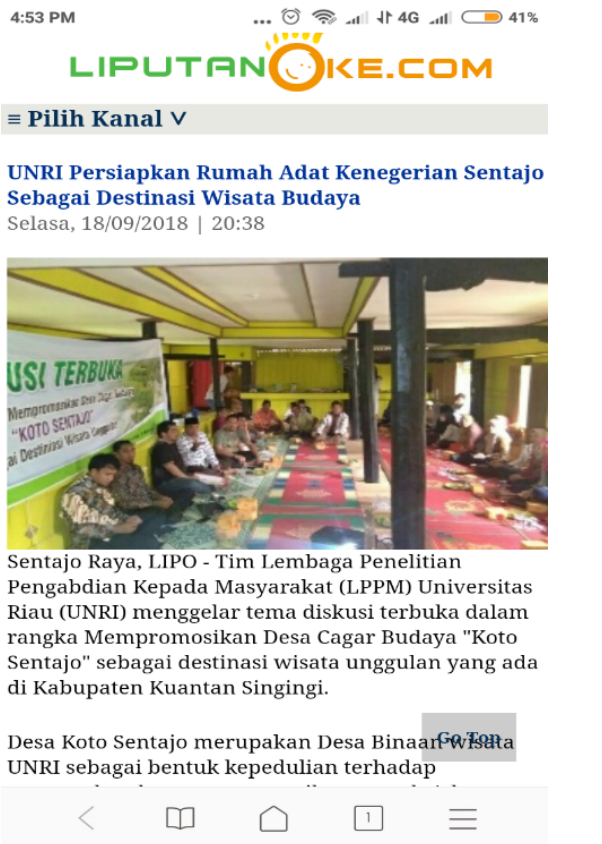 \\
\hline
\end{tabular}




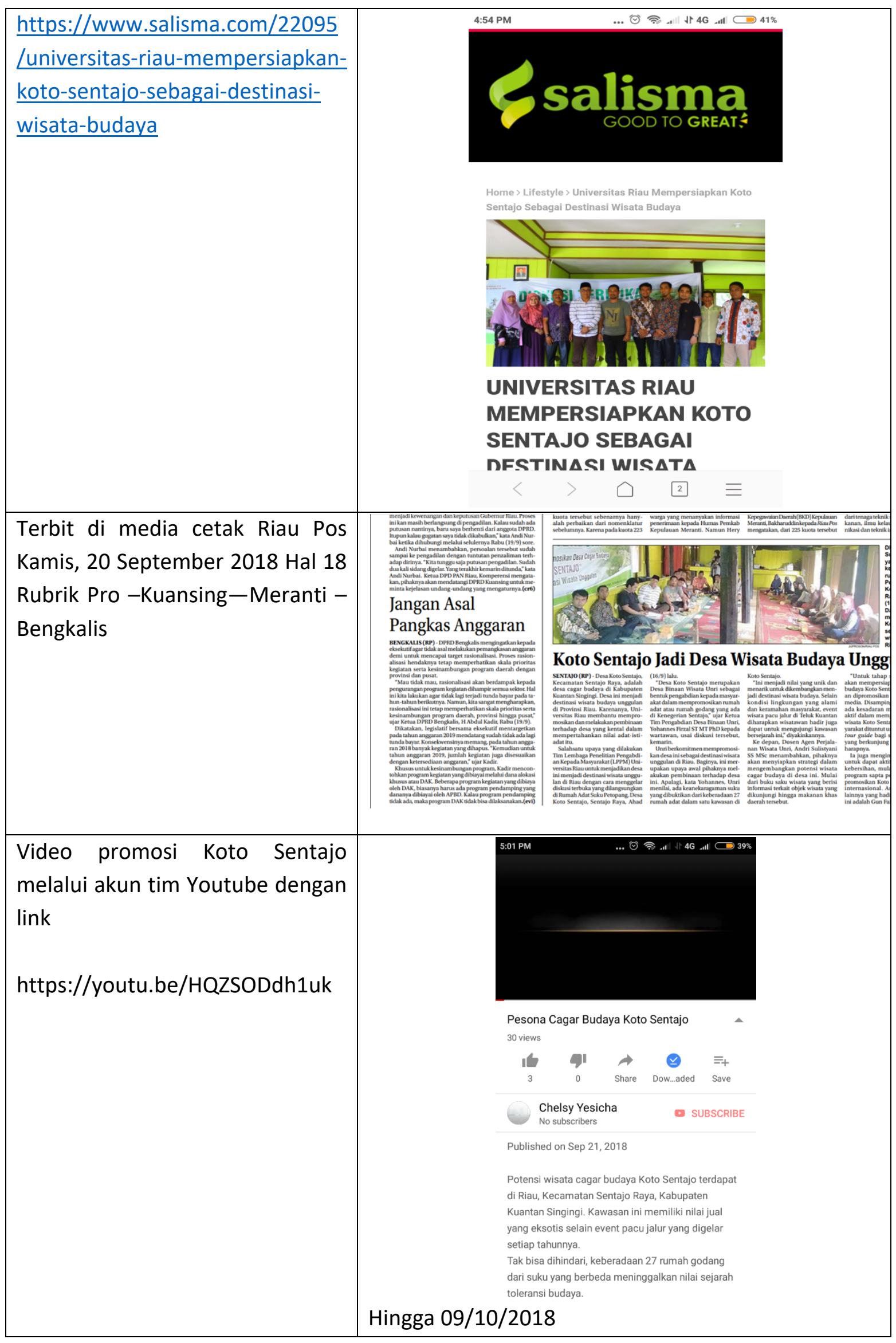




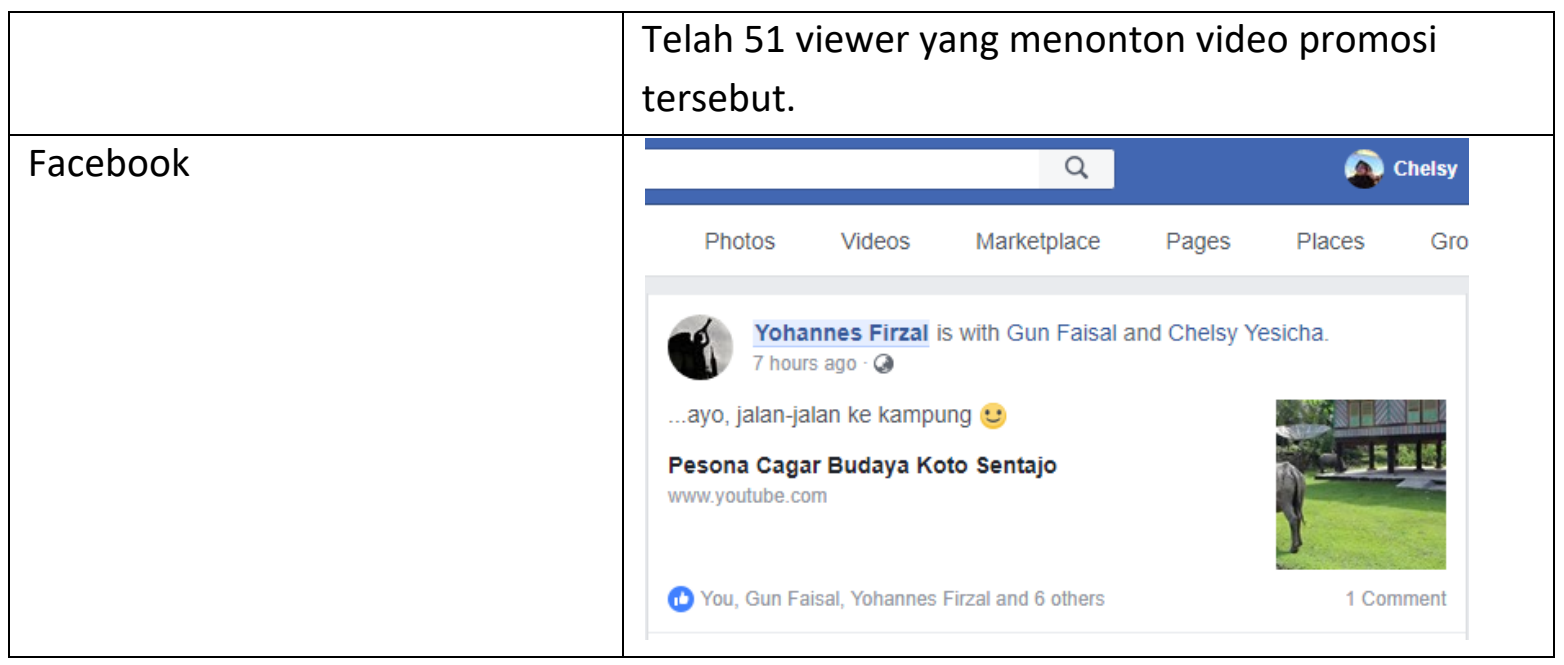

\section{SIMPULAN}

Antusias masyarakat Desa Koto Sentajo yang sangat minim ditambah kegiatan POKDARWIS dalam mempromosikan wisata budaya yang dinilai sangat pasif. Hal ini karena kuatnya masyarakat memegang nilai dan norma adat yang menganggap wisatawan dan pembukaan daerah mereka sebagai objek wisata akan merusak kemurnian nilai adat dan budaya mereka.

Adanya upaya-upaya yang dilakukan tim pengabdian bersama perangkat desa meningkatkan minat dan antusias masyarakat melalui POKDARWIS sehingga diharapkan masyarakat Desa Koto Sentajo kedepannya bisa mandiri mengelola potensi desa Koto Sentajo dan meningkatkan pemasukan daerah.

Beberapa kegiatan yang telah dilakukan oleh tim pengabdian bersama POKDARWIS dalam upaya mempromosikan wisata budaya Rumah Godang di Desa Koto Sentajo antara lain pembuatan peta desa dan flyer desa, buku saku kuliner Desa Koto Sentajo, pelatihan public speaking dan pelatihan pemandu wisata yang meliputi kemampuan berbicara, grooming dan personality development.

\section{DAFTAR PUSTAKA}

Pitana, I.G., \& Diarta, I.K.S. (2009). Pengantar Ilmu Pariwisata. Andi Publisher.

Rahmi, F. (2012). Pedoman Kelompok Sadar Wisata. Kemenpar.

Suryawan, A. (2016). Peran Kelompok Sadar Wisata (POKDARWIS) Sendang Arum Dalam Pengembangan Potensi Pariwisata (Studi Kasus di Desa Wisata Tlahap Kecamatan Kledung Kabupaten Temanggung). Jurnal Elektronik Mahasiswa Pend. Luar Sekolah S1, 5(6), 143-152. 